\title{
Multi-Level Governance of COVID-19 Pandemic and the Solitude Within Geriatric Oncology
}

\author{
Vasco Lourenço Fonseca ${ }^{1,2 \star}$, Joaquim Croca Caeiro ${ }^{1}$ and Rui Miranda Juliao ${ }^{1}$ \\ ${ }^{1}$ Centre of Public Administration and Public Policies, Institute of Social and Political Sciences, Universidade de Lisboa, \\ Lisboa, Portugal, ${ }^{2}$ Centro Hospitalar de Lisboa Ocidental, E.P.E., Lisboa, Portugal
}

Keywords: governance, solitude, geriatric oncology, public health, cancer, COVID-19

OPEN ACCESS

Edited by:

Marcia G. Ory,

Texas A\&M University, United States

Reviewed by:

Roger Chammas,

University of São Paulo, Brazil

Tony Kuo,

UCLA Fielding School of Public

Health, United States

*Correspondence:

Vasco Lourenço Fonseca

vfonseca@chlo.min-saude.pt

Specialty section:

This article was submitted to Aging and Public Health,

a section of the journal

Frontiers in Public Health

Received: 29 December 2020

Accepted: 26 March 2021

Published: 29 April 2021

Citation:

Fonseca VL, Caeiro JC and Juliao RM (2021) Multi-Level Governance of COVID-19 Pandemic and the Solitude Within Geriatric Oncology. Front. Public Health 9:647444. doi: 10.3389/fpubh.2021.647444
Present worldwide governance deals with people's effectively and justly performance (1). Nowadays, governance presumes a social constructionist strategy led by the government. As the central policymaker, a nation's state administration decides social and economic resources towards its development. This faculty of formulating, planning, and fulfilling tasks coordinate the nature of rule patterns. It gives place to new governing practices that require accurate initiatives, from which emerge new theories that give birth to different dilemmas. The relationship between state and societies changes once the governing activity works with non-governmental organizations, like private companies and non-profitable service providers (2).

Global governance is a set of regulations developed to answer specific issues, national or regional, or to supply transnational common goods (3). It also refers to multilevel governance when tasks are separated by sector and not by level, which results in a highly concentrated network of outstanding quality international and transnational institutions. These are far more intrusive than conventional international ones. On the one hand, they can resist national political governance by the decisionmaking of the majority. On the other, they can sort out disputes both by transnational means' monitoring and knowledge control and interpretation (3). In the globalization era, nations favour global organisations since are commonly accepted and have the authority to decide for millions of people. Simultaneously, they restrict international regulation based on the national sovereignty and their vetting ability.

Public and private organisations have their own administration. As a rule, management includes not only decision-making but also social intervention. We usually include the political element, which is extremely relevant for public administration. This is the most substantial difference from private organisations. The Public Administration Sciences acknowledges plus providers of goods and services towards the satisfaction of the communities (3). Additionally, they check the public policies arrangement to resolve difficulties, by using the resources available. Although significant differences, public administration answers to political government. While the public administration, despite some unreasonable behaviours and theories, relies on a regulated, objective and scientific thought, governmental politics is more subjective and intuitive, and less formal (3).

Circulating everywhere, most people contaminated by the newly discovered coronavirus (COVID-19) will experience mild to moderate respiratory illness and recover well. Others, especially the cardiovascular, diabetes, chronic respiratory and cancer ones, are more likely to develop severe illness (4). Elderly and cancer patients are at increased risk of obtaining COVID-19 and dying from it. Moreover, older people with cancer are at the highest risk of being excluded from intensive care support for COVID-19 infection and adequate cancer treatment if resources are restricted. Global improvement in health care and living conditions has generated an ageing population, and, by 2020, we had more than 700 million at an advancing age and high-risk cancer factor worldwide (5). Likewise, loneliness is a known risk factor for poor mental and physical health outcomes and quality of life in the general population, and preliminary research suggests 
that loneliness relates to poorer health outcomes in cancer patients (6).

Leadership is essential for governance; it bonds reputation to performance. Isabel Fonseca defends that despite society's perception of ethical politic behaviour, the media can either amplify or lessen it (7).

Ancient philosophy's ethics embraced both social behaviour and a high living standard and, politically and jurisdictionally, ought to be sovereign to survive (8). Economically speaking in politics, the most important for a liberal democracy was to assure society's endurance. As per Adam Smith's “invisible hand," the stock market is essential to aid the worlds progression with minimal national intervention. In other words, if the stock market shuts down, our economic model collapses (9). Medical ethical principles were inspired on a scientific model created during the era of Illuminism, and later developed into the present biomedical model. For therapeutic specialists, bioethics means to make the best evidence-based practice available to every patient. Presently, the commonly called oriented treatment is considered the most accurate. However, it doesn't consider the social condition of patients (10), although we presume everybody has equal access to the most advanced treatment. Yet, the health model used in the East is based on combating diseases and promoting health. Lalonde, a prominent supporter, advocated that better health outcomes is achieved through several healthcare programs like vaccination prevention and sanitary improvements, which in turn has a holistic approach $(11,12)$. Vaccination is a biosocial approach for a sustainable health procedure. It is also a political determinant because it results from a political decision and strategy. Group immunization is accomplished by mass vaccination and is the best health policy to handle pandemics. Vaccines have proved to be safe, and the elderly with cancer shall be a priority. As a result of a politic policy executed by public administration, this biosocial strategy will contribute to social and health progress (13).

The current health systems are based on the biomedical model and scientific evidence with an intricate hospital practice approach (12). The World Health Organization (WHO), national governments and medical scientific communities have a unique role in the governance of health systems, in scientific knowledge communication and implementation of good health practices (4).

WHO plays a vital role in global health systems governance by establishing values seemingly familiar to every country, helping to regulate health policies. Some relate to a western perspective on the world, like individual freedom and science, which are considered key factors in a nation's development. Such multilevel governance might need to reflect on incorporating other cultures' elements to ensure a common understanding, like China's holistic approach to health care (12). The national health systems will gradually integrate these, while WHO will face the challenge of a global world that needs to both respect cultural distinctions and focus on its development.

In 2020, due to COVID-19, health systems face enormous challenges and demands. It became clear that we cannot approach this pandemic using the current complex approach model. COVID-19 awakened the global population towards local health organisations in general (authorities, hospitals, and local primary healthcare providers). It forced health systems worldwide to adapt their assistance to the population. In some instances, national decision-makers have chosen public policies according to the prevailing classic paradigm (14).

The WHO guidelines supersede national policies and limit public health policies. The pandemic health comebacks have been implemented through a multilevel government approach governance $(15,16)$. The strategy and efficiency of such answer varies between countries within the European Union territory, which proves that the political power still prevails over health specialists and professionals $(1,16)$.

As a response to the pandemic in Portugal, the WHO acting above the national level, and the DGS - Direção Geral de Saúde (National Health Administration) acting at a national level, are the driving forces for public health. Citizens know that scientists inform politicians with specific data, reports, scenario analyses and solutions in the current emergency state in healthcare. There are frequent meetings and the information is regularly made public (17).

The implementation of public health measures (personal protective equipment), isolation and social distance, are major solutions. Social isolation and the subsequent procedures for social distance like online working, is changing the relationship between healthcare professionals and their patients. Telemedicine increased, and so did solitude and its negative impact on physical and mental health. Despite being a growing issue in our society, the elderly has been the most affected (18). As social bonds decrease, the risk of loneliness goes up, and loneliness affect people from different socioeconomic backgrounds and age. Although regarded as a healthcare problem, solitude is still stigmatised, ostracised, and even ignored in some cultures (6).

Solitude is a risk factor for mental and neurologic diseases like depression and cognitive disorders (6). It is also related to the immune system, sleep disorders, pain, tiredness, and cancer (5). The bidirectional relationship between cancer and solitude subsists, mainly because cancer can contribute to loneliness. On the one hand, patients with cancer hold either more significant apprehensions about existence or unrealistic expectations. On the other, they fear to share their perceptions. Encouraged, seemingly, by relatives, some of the patients reveal constrained social behaviours like blame, shame or avoidance mainly when the subject is cancer, leading to seclusion behaviours. There are several social determinants like the fragility of the geriatric patient derived from isolation or frequently living in a senior residence, away from family and friends (5). The patient with cancer has an increased bias to loneliness due to age, debility, and his own experience of dealing with the disease. Administration boards for health institutions must deliver a specific social intervention to combat seclusion and negative expectations towards cancer $(5,6)$. The cancer patient belongs to the high-risk group of COVID-19 and needs specific answers according to the European Society of Medical Oncology (ESMO) and the International Society of Geriatric Oncology (SIOG). Both SIOG, WHO and DGS (Portuguese National 
Health Administration) give physicians guidelines to prepare them to answer adequately to elderly cancer patients. As developed societies, we cannot neglect elders or risk failing as a civilisation (19).

COVID-19 pandemic is a challenge to medical and social response, which drive health institutions' administrations to coordinate different arrangements. These new public health policies should lead the way to an adequate resolution to specific questions concerning the pandemic. It must still have the ability to implement those policies and procedure plans promptly. Innovation in healthcare amongst a pandemic scenario will surely produce fundamental changes for the future (20).

Medical professionals consider themselves specialists, not protagonists. During this battle, physicians and nurses have succumbed as soldiers of the latest biological warfare. Given this "combatant" status, we acknowledge that in a modern society, the public healthcare specialists' assignment should be reassessed (18).

\section{REFERENCES}

1. Rajan D, Koch K, Rohrer K, Bajnoczki C, Socha A, Voss M, et al. Governance of the Covid-19 response: a call for more inclusive and transparent decisionmaking. BMJ Glob Health. (2020) 5:e002655. doi: 10.1136/bmjgh-2020-002655

2. Bevir M (editor). The Sage Handbook of Governance. London: Sage Publications, Ltd. (2011).

3. Carvalho E. Decisão na Administração Pública: diálogo de racionalidades. Sociol Problemas Práticas. (2013) 73:131-48. doi: 10.7458/SPP2013732811

4. World Health Organization (2020). Available online at: https://www.who.int/ news-room/releases

5. Adams R, Mosher C, Rand K, Hirsh A, Monahan P, Abonour R, et al. The cancer loneliness scale and cancer-related negative social expectations scale: development and validation. Quality Life Res. (2017) 26:190113. doi: 10.1007/s11136-017-1518-4

6. Cacioppo J, Hawkley L. Perceived social isolation and cognition. Trends Cogn Sci. (2009) 13:447-54. doi: 10.1016/j.tics.2009.06.005

7. Fonseca I. Da Luz às Luzes. Lisboa: ISCSP, (2001).

8. Zurn M. Global Governance as Multi-Level Governance. The Oxford Handbook of Governance. New York, NY: Oxford University Press Inc. (2012). doi: 10.1093/oxfordhb/9780199560530.013.0051

9. Smith A. A Riqueza das Nações. In: Nova Cultural, Nações "Os Economistas". São Paulo (1988)

10. Fonseca V, Caeiro J. Bioethics and healthcare policies. The benefit of using genetic tests of BRCA 1 and BRCA 2 in elderly patients. Int J Health Plann Mgmt. (2020) 36:18-29. doi: 10.1002/hpm.3072

11. Lalonde M. A New Perspective on the Health of Canadians. Ottawa, ON: Government of Canada (1974).

12. Justo C. A crise do modelo biomédico e a resposta da promoção da saúde. Rev Port Saúde Pública. (2010) 28:117-8. doi: 10.1016/S0870-9025(10)70001-8

13. Mislang AR, Soto-Perez-de-Celis E, Russo C, Colloca G, Williams GR, O'Hanlon S, et al. The SIOG COVID-19 working group recommendations on the rollout of -covid-19 vaccines among older adults with cancer. J Geriatr Oncol. doi: 10.1016/j.jgo.2021.03.003. [Epub ahead of print].

\section{AUTHOR CONTRIBUTIONS}

VF conceived the subject and managed the entirety of the study including data entry and writing. JC supervised the study and provided relevant subject matter consultation and advice. RJ provided valuable assistance with literature review and study design.

\section{FUNDING}

This work was supported by Portuguese national funds through FCT - Fundação para a Ciência e a Tecnologia Grant Number: Project UIDP/00713/2020).

\section{ACKNOWLEDGMENTS}

Centro Hospitalar de Lisboa Ocidental Universidade de Lisboa, Instituto Superior de Ciencias Sociais e Políticas.

14. Weible C, Nohrstedt D, Cairney P, Crow DA, Durnová AP, Heikkila $\mathrm{T}$, et al. COVID-19 and the policy sciences: initial reactions and perspectives. Policy Sci. (2020) 53:225-41. doi: 10.1007/s11077-02009381-4

15. Hooghe L. The European Commission and the integration of Europe: Images of Governance. Cambridge: Cambridge University Press (2002).

16. Hooghe L, Marks G. Types of Multi-Level Governance. European Integration Online Papers 5 (2001). Available online at: https://www.researchgate.net/ publication/48854082_Types_of_Multi-Level_Governance

17. DGS - Direção Geral de Saúde. Publicações (2020). Available online at: https:// www.dgs.pt/documentos-e-publicacoes/plano-da-saude-para-o-outonoinverno-2020-2021.aspx

18. ESMO - European Society for Medical Oncology (2020). Oncology news prolonged isolation may be detrimental for elderly cancer patients during the pandemic. Available online at: https://www.esmo.org/oncology-news/ prolonged-isolation-may-be-detrimental-for-elderly-cancer-patientsduring-the-pandemic

19. SIOG - International Society of Geriatric Oncology (2020). Available online at: http://www.siog.org

20. Fauci A, Lane C. Redfield R. Covid-19 - navigating the uncharted. N Engl J Med. (2020) 382:1268-9. doi: 10.1056/NEJMe2002387

Conflict of Interest: The authors declare that the research was conducted in the absence of any commercial or financial relationships that could be construed as a potential conflict of interest.

Copyright (c) 2021 Fonseca, Caeiro and Juliao. This is an open-access article distributed under the terms of the Creative Commons Attribution License (CC BY). The use, distribution or reproduction in other forums is permitted, provided the original author(s) and the copyright owner(s) are credited and that the original publication in this journal is cited, in accordance with accepted academic practice. No use, distribution or reproduction is permitted which does not comply with these terms. 